\title{
ESTIMATIVA DA PRODUTIVIDADE EM GENÓTIPOS DE PALMA FORRAGEIRA (Nopallea cochenilífera) CULTIVADOS EM DIFERENTES ADUBAÇÕES.
}

Cássio Gyovanne de Aquino Amoim ${ }^{1}$; Adriana Rodrigues Passos²; Mariana Santos de Jesus $^{3}$ e Quarto Autor

1. Bolsista PIBIC/UEFS, Graduando em Agronomia, Universidade Estadual de Feira de Santana, e-mail: cassiogyovanneagro@hotmail.com

2. Orientadora, DCBIO, Universidade Estadual de Feira de Santana, e-mail: adrianarpassos@yahoo.com.br 3. Doutoranda, Participante do projeto, DCBIO, Universidade Estadual de Feira de Santana, e-mail: maryanamell@gmail.com

4. Graduanda em Agronomia participante do projeto, Universidade Estadual de Feira de Santana, e-mail: jady fcg@hotmail.com

\section{PALAVRAS-CHAVE: Nopalea cochenillifera, Produtividade, Caracterização}

\section{INTRODUÇÃ̃O}

A palma forrageira é nativa do México (Reyes-Aguero et al., 2005) e foi introduzida no Brasil por volta de 1880, no estado de Pernambuco, através de sementes importadas do Texas - Estados Unidos, apresentando boa adaptação (Silva e Carvalho, 2006). A espécie pertence à família das cactáceas, na qual existem 178 gêneros com cerca de 2.000 espécies conhecidas. Todavia, as espécies Opuntia fícus - indica e Nopalea cochenillifera Salm - Dyck, compreendem as espécies mais utilizadas como forrageiras.

A adubação da palma, independentemente da cultivar utilizada, induz incremento da área foliar e de matéria seca, refletindo no crescimento da planta e, consequentemente, na produtividade, o que acontece também para o plantio adensado e para a adubação orgânica associada à adubação química (Almeida, 2011). Os experimentos com adubação em palma forrageira no Brasil evidenciaram respostas significativas da cultura às adubações realizadas tanto do ponto de vista quantitativo como qualitativo (Leite, 2009).

Dessa maneira, a realização de testes utilizando diferentes fontes de nutrientes na adubação do solo para o plantio da palma miúda (Nopalea cochenillifera SalmDyck) se torna de suma importância, visto que, o incremento na produção de biomassa utilizando fontes de adubo adequadas e economicamente viáveis poderá garantir melhor uso do solo e maior disponibilidade de forragem para os animais.

\section{MATERIAL E MÉTODOS}

O experimento foi conduzido na Unidade Experimental Horto Florestal, localizada na cidade de Feira de Santana, na região do semiárido baiano.

Para implantação da área experimental foram utilizados dois genótipos provenientes de programas de melhoramento da palma forrageira: o clone V26; e o clone IPA Sertânea, ambos pertencentes à espécie Nopalea cochenillifera Salm- Dyck. Antes do plantio, coletou-se e realizou-se a análise de solo da área a fim de se conhecer suas características e ter como base para cálculos de possíveis correções e doses de adubação. O preparo da área foi realizado com capina manual.

O delineamento experimental foi em blocos ao acaso, em esquema fatorial $3 \times 2 \times 2$ (tratamentos, genótipos e épocas), com três repetições. Cada bloco foi formado pelos 
tratamentos: (T1) sem adubação, (T2) esterco bovino (15 t ha $\left.{ }^{-1}\right)$ e (T3) adubo químico NPK (nitrogênio, fósforo e potássio) conforme recomendação agronômica com base na análise de solo: Uréia: $100 \mathrm{~kg} / \mathrm{ha}$; Fósforo: $200 \mathrm{~kg} / \mathrm{ha}$ e Potássio: $100 \mathrm{~kg} / \mathrm{ha}$. Cada genótipo foi disposto em três fileiras contendo dez plantas cada, totalizando 30 plantas por tratamento, dentro de cada bloco. No plantio foi utilizado um cladódio por cova, na posição vertical, com a porção cortada voltada para o solo, na profundidade a evitar o tombamento, obedecendo ao espaçamento de 1,0 x $0,5 \mathrm{~m}$ (fileiras e plantas). O plantio foi realizado no mês de agosto de 2016 .

A determinação da massa verde das plantas foi realizada oito meses após o planto. As plantas foram coletadas e pesadas com auxilio de balança digital. Posteriormente, os cladódios foram submetidos à secagem em estufa de ventilação forçada a $65^{\circ} \mathrm{C}$, por um período de quinze dias para determinação da massa seca por diferença de peso. A estimativa de produção por hectare foi obtida pela expressão: $\left(M^{2} T^{*} 10000\right) / 8$, sendo MST o peso da matéria seca em cada tratamento, seguindo metodologia descrita por Silva e Queiroz (2009).

A avaliação morfoagronômica foi realizada aos quatro e oito meses após o plantio. Nestas, foram tomadas as medidas da planta e do cladódio. Na planta foram avaliadas as seguintes características: altura total, largura e número total de cladódios. Para avaliação dos cladódios foram tomadas a medidas de três cladódios por planta, avaliando os seguintes caracteres: comprimento, largura e diâmetro. A área de cada cladódio foi determinada conforme descrito por Cortázar e Nobel (1991), com base na expressão: $\mathrm{AC}=$ comprimento $\mathrm{x}$ largura $\mathrm{x}$ 0,632. A área fotossintética total da planta foi obtida pela multiplicação da área do cladódio pelo número total de cladódios (OLIVEIRA JR. et al., 2009).

Foram efetuadas as análises de variância, combinadas e desdobradas entre época, genótipos e tratamentos; cálculo das diferenças mínimas significativas (LSD) para o nível de $5 \%$ de probabilidade de erro, utilizando-se o quadrado médio das interações genótipo-ambiente; cálculo dos coeficientes de correlação entre os caracteres agronômicos das plantas. As análises foram realizadas utilizando o aplicativo GENES (CRUZ et al., 2004), aplicando-se teste F, média e coeficiente de variação experimental

\section{RESULTADOS E/OU DISCUSSÃO}

$\mathrm{Na}$ Tabela 1 foram apresentados os valores de quadrado médio e seus níveis de significância para os descritores que determinaram a produtividade do experimento. $\mathrm{Na}$ fonte de variação blocos x genótipos e na interação genótipo x tratamento, não houve diferenças significativas no descritor avaliado, enfatizando bom controle experimental, não havendo diferenças quanto a produtividade entre os genótipos trabalhados. Para a fonte de variação tratamentos, o descritor produtividade de matéria seca (PRODMS) foi altamente significativo, o que indica que a fonte de adubação utilizada inferiu diretamente no fator de maior importância do experimento.

Tabela 1. Análise de variância e o coeficiente de variação experimental para produtividade de matéria seca (PRODMS) $(\mathrm{Kg} / \mathrm{Ha})$ avaliadas em dois clones de palma miúda (Nopalea cochenillifera Salm- Dyck) cultivados sob diferentes fontes de adubação e avaliados ao final do experimento (8 meses).

\begin{tabular}{llc}
\hline FV & & QUADRADO MÉDIO \\
\hline & GL & PRODMS \\
Blocos & 2 & $188547.068^{\text {ns }}$ \\
Tratamentos & 2 & $2217828.143^{* *}$ \\
Genótipo & 1 & $25785.463^{\text {ns }}$ \\
\hline
\end{tabular}




\begin{tabular}{lcc}
\hline T X G & 2 & $13459.289^{\text {ns }}$ \\
Resíduo & 4 & 91536.455 \\
CV (\%) & & 20.67 \\
\hline
\end{tabular}

T x G= interação tratamento e genótipo, ns = Não significativo, * = Significativo no nível de $5 \%$ de probabilidade pelo teste $\mathrm{F}, * *=$ Significativo no nível de $1 \%$ de probabilidade pelo teste $\mathrm{F}$.

$\mathrm{Na}$ Tabela 2, foram apresentados os valores médios e respectivas formações de grupos para o caractere que determinou a produtividade do experimento. A partir dos dados, pode-se observar a formação de um grupo estatisticamente superior pelo teste de Scott-Knott ao nível de 5\% de significância, para o tratamento onde se utilizou esterco nos dois genótipos utilizados, em relação ao tratamento testemunha e ao tratamento utilizando fertilizantes químicos. Não se observou a formação de grupos distintos para os genótipos utilizados, entre os três tratamentos.

Segundo Braga (2010), além de fornecer nutrientes, os adubos orgânicos melhoram a estrutura física, química e biológica e aumentam a CTC (capacidade de troca de cátions) do solo. Sua decomposição é lenta e os nutrientes são liberados em menor quantidade para as plantas, contribuindo também para o acúmulo de matéria orgânica no solo. Dessa forma, sendo a palma forrageira uma cultura perene, a adubação de fundação a base de fontes de adubo orgânico entra como excelente alternativa, visto que irá inferir em maior produção de matéria seca ao longo do seu ciclo produtivo através da liberação lenta dos seus nutrientes e melhoria das características físicas, químicas e biológicas do solo. Além do mais, tratando-se de aspectos econômicos, a utilização do esterco tem maior viabilidade, já que é um recurso barato e na maioria das vezes disponível dentro da propriedade ou em fazendas próximas que desenvolvem pecuária, se enquadrando na realidade da maioria dos agricultores familiares do Nordeste.

Tabela 2. Valores médios para produtividade de matéria verde (PRODMV) $(\mathrm{Kg} / \mathrm{Ha})$ e produtividade de matéria seca (PRODMS) $(\mathrm{Kg} / \mathrm{Ha})$ avaliadas em dois genótipos de palma miúda (Nopalea cochenillifera Salm- Dyck) cultivados sob diferentes fontes de adubação.

\begin{tabular}{ll}
\hline FONTE & \multicolumn{1}{c}{ VARIÁVEL } \\
\cline { 2 - 2 } TESTEMUNHA IPA-SE & PRODMS \\
TESTEMUNHA V26 & $1123.16 \mathrm{~B}$ a \\
ESTERCO IPA-SE & $1142.54 \mathrm{~B} \mathrm{a}$ \\
ESTERCO V26 & $2249.98 \mathrm{~A} \mathrm{a}$ \\
QUÍMICO IPE-SE & $2079.92 \mathrm{~A} \mathrm{a}$ \\
QUÍMICO V26 & $1130.34 \mathrm{~B}$ a \\
\hline
\end{tabular}

Médias seguidas pelas mesmas letras maiúsculas na mesma coluna constituem grupo estatisticamente homogêneo pelo teste de Scott-Knott ao nível de 5\% de significância para a variável tratamento. Médias seguidas pelas mesmas letras minúsculas no mesmo tratamento constituem grupo estatisticamente homogêneo pelo teste de Scott-Knott ao nível de 5\% de significância para genótipos.

\section{CONSIDERAÇÕES FINAIS}

- O experimento conduzido demonstrou haver diferenças estatísticas quanto à fonte de adubo utilizada para a adubação da palma forrageira miúda (Nopalea cochenillifera Salm- Dyck);

- A época de avaliação interferiu significativamente nos resultados obtidos, havendo maior produtividade para a idade mais avançada das plantas;

- O tratamento onde se utilizou adubação orgânica apresentou maior produtividade de MS em relação aos tratamentos testemunhas sem adubação e com adubo químico; 


\section{REFERÊNCIAS}

ALMEIDA, J. A palma forrageira na Região Semiárida do Estado da Bahia:

diagnóstico, crescimento e produtividade. Tese (Doutorado) - Centro deCiências

Agrárias, Ambientais e Biológicas - Universidade Federal do Recôncavo da Bahia. Cruz das Almas-BA. 95f. 2011.

BRAGA, G.N.M. A Importância e o manejo da Adubação Orgânica. Disponível em:. Acesso em: 27.jul.2017.

CRUZ, C.D.; REGAZZI, A.J.; CARNEIRO, P.C.S. Modelos biométricos aplicado ao melhoramento genético. $3^{\circ}$. ed. Viçosa: ed. Universitária da UFV. v. 1, 2004, p.180-192.

CORTAZAR, V.; NOBEL, P.S. Prediction and measurement $\mathrm{f}$ high annual productivity for Opuntiaficus-indica.Agricultural and Forest Meteorology, v. 56, p. 261-272., 1991.

LEITE, M.L.M.V. Avaliação de clones de palma forrageira submetidos a adubações e sistematização de informações em propriedades do Semiárido paraibano. Tese (Doutorado em Zootecnia) - Centro de Ciências Agrárias. Universidade Federal da Paraíba, Areia. 186f. 2009.

OLIVEIRA, J.; QUEIROZ, S. R. O. D; AYALA-OSUNA, J. T. Melhoramento genético da palma forrageira visando aumentar a qualidade e produção para o consumo animal e humano. Relatório parcial de pesquisa - FAPESB. 2009, 25p.

REYES-AGUERO, J.A.; AGUIRRE-RIVERA, J.R.; HERNÁNDEZ, H.M. Notas sisteméticas y descripcióndetallada de Opuntiaficus-indica (L) Mill. (Cactáceae). Agrociência, v. 39, n. 4, p. 395-408, 2005.

SILVA, F. C. C.; CARVALHO, L. Palma Forrageira (Opuntia Fícus- Indica Mill) como alternativa na alimentação de ruminantes. Revista Eletrônica de Veterinária- REDVET, Vol. VII n ${ }^{\circ}$ 10, Out. 2006.

Silva, D. J.; Queiroz, A. C. Análise de alimentos: métodos químicos e biológicos. 3.ed. Viçosa: UFV, 2009. 235p. 